Administrative changes could improve completeness and quality and make it a better tool for surveillance of risk. The CDR is potentially the most complete source of information. If death certificates for accidental deaths have incomplete data, the certifier could more often be asked to provide missing information. Validation by casewise comparison between NLIA and CDR with regular intervals is recommended.

\section{INCIDENCE, IMPACT, MEDICAL CONSEQUENCES OF UNINTENTIONAL CHILDHOOD INJURIES IN A RURAL BLOCK IN SOUTH INDIA}

'Leeberk Raja Inbaraj, ${ }^{2}$ Anuradha Rose, ${ }^{2}$ Kuryan George, ${ }^{2}$ Anuradha Bose. ${ }^{1}$ Bangalor Baptist Hospital, Bangalore, India; ${ }^{2}$ Christian Medical College, Vellore, India

\subsection{6/injuryprev-2016-042156.476}

Background Unintentional childhood injury is a major cause of mortality and morbidity among children (upto 18 years) across the globe and contributes to over 875,000 deaths annually worldwide. Global Childhood Unintentional Injury Surveillance estimates that nearly $50 \%$ of children under 12 years suffered severe unintentional injuries leading to some form of disability. Unintentional childhood injury is an under-reported public health problem in India. This study was undertaken to estimate the incidence and assess economic impact and medical consequences of unintentional childhood injuries among children between $0-14$ years. Methods This is a non-concurrent cohort study, conducted in 13 clusters of a rural block in Vellore. Double stage cluster sampling method was used to screen 1600 children with injury. Information regarding the impact and consequences of injury was obtained.

Results Childhood injury related morbidity was 292.5/1000/year. Children between 10-14 years (4.6\%) and boys (4.5\%) had a higher rate of injury. Majority of injuries occurred at home $(44.8 \%)$ and most commonly on the lower extremity $(51.7 \%)$. Falls $(43.1 \%)$ was the most common cause of injury followed by RTIs (27.6\%). The direct medical and non medical cost of treatment ranged from \$US0.14 to \$US74. The wages lost by the primary caregiver ranged from \$US1.4 to \$US90 and absenteeism from work ranged from 1-60 days. Sick absenteeism ranged from 0-45 days with a mean of 5.17 days. $50 \%$ of children missed school after an injury. The days spent with temporary disability ranged from 1-60 days with a mean of 4.08 days and $7.73 \%$ had permanent disability.

Conclusion Unintentional childhood injuries is an emerging public health problem which leads to significant injury related sickness absenteeism and disability. Boys and older children are the most common victims of injury. Prospective trials on the economic impact and medical consequences will help to gain a clear understanding of DALY and loss of productivity.

\section{INJURY RISK IN FINNISH YOUTH FLOORBALL: A ONE- YEAR PROSPECTIVE FOLLOW-UP STUDY}

${ }^{1}$ Kati Pasanen, ${ }^{1}$ Jussi Hietamo, ${ }^{1}$ Pekka Kannus, ${ }^{1}$ Tommi Vasankari, ${ }^{2} U$ rho Kujala, ${ }^{2}$ Ari Heinonen, ${ }^{1}$ Jari Parkkari. ${ }^{1}$ UKK Institute for Health Promotion Research, Finland; ${ }^{2}$ University of Jyväskylä, Finland

\subsection{6/injuryprev-2016-042156.477}

Background Floorball is a popular team sport in Finland. Previous studies have revealed that injuries are a significant problem in adult floorball. However, epidemiological studies of injuries in youth floorball are lacking. The aim of this study was to investigate the incidence, type, and severity of injuries in young floorball players.

Methods One-hundred-fifty-six female $(\mathrm{n}=57)$ and male players $(n=99)$ (mean age $17.1 \pm 1.6$ years) from nine floorball teams participated in the study. Injury data as well as practice and game exposures were collected over the 12-months period (from May 2013 to April 2014). An injury was defined as having occurred in an organised floorball practice or game, and having resulted in the inability to participate in floorball training or playing for one or more days. Severity of injury was measured by number of days lost from floorball training and playing.

Results The players reported a total of 136 injuries, of which $63 \%$ were traumatic and $37 \%$ were from overuse. The overall incidence of injuries in female and male players per 1000 practice and game hours was 4.5 (95\% CI: 3.48 to 5.79 ) and $3.0(95 \%$ CI: 2.41 to 3.76 ), respectively. Incidence of traumatic gamerelated injuries in females was 45.1 per 1000 game hours $(95 \%$ CI: 30.98 to 65.67$)$, and 19.9 (95\% CI: 12.87 to 30.65$)$ in males. The majority $(76 \%)$ of injuries occurred in the lower extremity, and the most commonly injured body part was the ankle $(24 \%)$, followed by the knee $(23 \%)$ and the lower back $(13 \%)$. Thirty-three percentages of all injuries resulted in less than 1 week time-loss, $30 \%$ in 1 to 4 weeks time-loss, and $37 \%$ in more than 4 weeks time-loss from sports. Thirty-one players had over 8 -week absence from training due to a severe injury.

Conclusions The injury risk in youth floorball is high. The lower limb is the most commonly injured body area. Rather many of the injuries are severe resulting in long-term absence from sports.

\section{INJURIES IN CHILDREN WITH AUTISM SPECTRUM DISORDER: STUDY TO EXPLORE EARLY DEVELOPMENT (SEED)}

${ }^{1}$ Carolyn DiGuiseppi, ${ }^{2}$ Susan Levy, ${ }^{3}$ Gnakub N Soke, 'Steven Rosenberg, ${ }^{1}$ Katherine R Sabourin, ${ }^{4}$ Li-Ching Lee, ${ }^{1}$ Eric Moody, ${ }^{3}$ Laura Schieve. ${ }^{1}$ University of Colorado Anschutz Medical Campus, USA; ${ }^{2}$ University of Pennsylvania, USA; ${ }^{3}$ Centers for Disease Control and Prevention, USA; ${ }^{4}$ Johns Hopkins University, USA

\subsection{6/injuryprev-2016-042156.478}

Background Studies of injury risk in children with autism spectrum disorder (ASD) have shown conflicting results. We examined medically-treated injuries in children with ASD vs. population (POP) controls.

Methods The Study to Explore Early Development (SEED) is a multi-site ASD case-control study of children aged 30-68 months. ASD cases $(n=693)$ were determined using established ASD-specific diagnostic instruments. POP controls $(n=882)$ were ascertained from birth certificates. Each child's primary caregiver reported if the child ever had a medically-treated injury and described each such injury. Injuries resulting in emergency department visit or hospitalisation were defined as "serious." We describe the nature and cause of each child's first reported injury. Associations between ASD and having at least one medicallytreated injury and serious injury were examined using logistic regression, adjusted for child sex, age, and IQ; maternal race/ethnicity and education; and family income.

Results Among children with ASD, 33\% ever had a medicallytreated injury and 25\% ever had a serious injury; the most commonly specified injuries were laceration (41\%), fracture (22\%) and abrasion/contusion (12\%). Among POP children, 30\% had a medically-treated injury and $22 \%$ a serious injury; the most commonly specified injuries were laceration (46\%), fracture $(23 \%)$ 